\title{
Postpartum depression on the neonatal intensive care unit: current perspectives
}

This article was published in the following Dove Press journal:

International Journal of Women's Health

24 November 2014

Number of times this article has been viewed

\author{
Noor N Tahirkheli' \\ Amanda S Cherry' \\ Alayna P Tackett ${ }^{2}$ \\ Mary Anne McCaffree ${ }^{3}$ \\ Stephen R Gillaspy'
}

'Section of General and Community Pediatrics, Department of Pediatrics, University of Oklahoma Health Sciences Center, Oklahoma City, OK, USA; ${ }^{2}$ Department of Psychology, Oklahoma State University, Stillwater, OK, USA; ${ }^{3}$ Section of NeonatalPerinatal Medicine, Department of Pediatrics, University of Oklahoma Health Sciences Center, Oklahoma City, OK, USA
Correspondence: Stephen R Gillaspy Section of General and Community Pediatrics, Department of Pediatrics, University of Oklahoma Health Sciences Center, 1200 Children's Avenue, Suite 12400, Oklahoma City, OK 73104, USA $\mathrm{Tel}+\mathrm{I} 405$ 27| 4407

Fax + I 405 27। 8709

Email stephen-gillaspy@ouhsc.edu
Abstract: As the most common complication of childbirth affecting $10 \%-15 \%$ of women, postpartum depression (PPD) goes vastly undetected and untreated, inflicting long-term consequences on both mother and child. Studies consistently show that mothers of infants in the neonatal intensive care unit (NICU) experience PPD at higher rates with more elevated symptomatology than mothers of healthy infants. Although there has been increased awareness regarding the overall prevalence of PPD and recognition of the need for health care providers to address this health issue, there has not been adequate attention to PPD in the context of the NICU. This review will focus on an overview of PPD and psychological morbidities, the prevalence of PPD in mothers of infants admitted to NICU, associated risk factors, potential PPD screening measures, promising intervention programs, the role of NICU health care providers in addressing PPD in the NICU, and suggested future research directions.

Keywords: neonatal intensive care unit, postpartum depression, mothers

\section{Introduction to postpartum depression and psychological morbidities}

Postpartum depression (PPD) is considered the most common mental health complication of childbirth. The Centers for Disease Control and Prevention estimates that approximately $15 \%$ of all mothers experience symptoms that meet criteria for a diagnosis of PPD in the United States. ${ }^{1}$ As many as $50 \%-80 \%$ of new mothers experience more typical postpartum symptoms including fatigue and mood swings. ${ }^{2}$ PPD is generally underidentified, underdiagnosed, and undertreated. ${ }^{3}$ Carrying substantial risk of morbidity, the affected population requires particular attention to address and improve methods of identification, intervention, and treatment. ${ }^{4}$

PPD has been shown to result in adverse effects for mothers, children, and the family, producing a multitude of negative consequences. ${ }^{3}$ Beck's meta-analysis showed that mothers with PPD exhibited several distinct patterns of behavior, including less affectionate behavior with the infant, less responsiveness to infant cues, withdrawn with a flat affect, and/or hostility and intrusiveness with their infants. ${ }^{5}$ Mothers with PPD also exhibit fewer positive parenting behaviors, such as playing with their children, continued breastfeeding, and taking safety precautions, such as the use of car seats. ${ }^{6}$ With a variety of accompanying medical concerns, NICU infants are already a vulnerable population. When compared to infants of normative mothers, infants of mothers with PPD were fussier, more discontent and avoidant, and made fewer positive facial expressions and vocalizations. ${ }^{5}$ Given their increased developmental vulnerability, 
increased need for stimulation, and decreased responsiveness, infants in the NICU are especially at risk for these types of outcomes. $^{7,8}$

For these infants, such changes in parenting behaviors are disconcerting and must receive scrupulous consideration and action to ensure the infant's well-being.

\section{Psychological morbidities}

Research consistently shows that the adverse effects of PPD can last long after NICU discharge. Upon discharge, these neonates continue to experience adverse physical and mental health/behavioral problems well into the school age and adolescent years. $^{8-13}$ In a study of 5-year-old children, PPD was related to the children's behavior problems at home and maladaptive social patterns of play at school. ${ }^{14}$ The effects of PPD are not limited to maladaptive emotional development. Sinclair and Murray found that 11-year-old children whose mothers had been depressed at 3 months postpartum had significantly lower intelligence quotient scores. ${ }^{14}$

Long-term negative outcomes of PPD are not limited to children. Mothers with PPD experience lasting psychological effects. Depressed mothers perceive more difficulties in the parenting role than do nondepressed mothers. ${ }^{15-22}$ This can lead to increased child behavioral issues, causing further parent-child conflict. ${ }^{15-22}$ Providing additional psychosocial resources to mothers with PPD could mitigate the lasting impact that PPD leaves on families.

\section{Search strategy}

From February 2013-August 2013, an electronic literature search was performed to identify articles for PPD prevalence, screening, and interventions in the NICU setting. The PubMed, MedLine, and PsycINFO databases were used. A Google Scholar search was employed to identify relevant articles that may have been missed in the database search. The following keywords and phrases were used: "neonatal intensive care unit"; "NICU infants"; "mothers of premature infants"; "mothers of preterm infants"; "mothers of low birth weight infants"; "premature infants in the NICU"; "preterm infants in the NICU"; "low birth weight infants in the NICU"; "mothers with PPD"; "mothers with PPD in the NICU"; "PPD in the NICU"; "depression in the NICU"; "infants in the NICU"; "emotional distress in the NICU"; "parents in the NICU"; and "stress in the NICU". Review articles and secondary references were further examined to identify additional primary articles for inclusion in the review. Approximately 100 abstracts were analyzed for possible inclusion.

\section{Inclusion criteria}

The results of the literature search yielded articles published between September 1972-August 2013. Thirty eight studies met inclusion criteria and were included in this review. The studies selected for inclusion focused on PPD, particularly PPD in mothers of infants hospitalized in the NICU for reasons including preterm birth, low birth weight (LBW), very low birth weight (VLBW), and other medical complications. Approximately 23 of the original 100 articles were referenced to provide basic background information regarding PPD. We excluded approximately 39 articles that did not focus on mothers of infants in the NICU. However, those 23 that provided essential universal information on PPD were included.

\section{Overall objectives of the current review}

The purpose of this article is to review the elevated prevalence of PPD and its associated risk factors in mothers of infants admitted to the NICU. We also discuss diagnostic criteria, screening measures, etiology, and risk factors associated with PPD, review promising intervention programs, discuss the role of health care providers in addressing PPD in the NICU, and identify future research directions.

\section{Prevalence of PPD in NICU mothers}

The mothers of infants admitted to the NICU are at greater risk for relationship difficulties, family stress, and financial stress when compared with mothers of healthy term infants. ${ }^{23}$ Vigod et al indicate that mothers of premature infants are $40 \%$ more likely to develop PPD, compared with the general population. ${ }^{24}$ Literature examining psychological maladjustment in mothers of infants admitted to the NICU reports that these women have consistently higher rates of PPD, ranging from $28 \%-70 \%,{ }^{25}$ compared with mothers of healthy term infants outside of the NICU.

Lefkowitz et al showed further evidence of higher PPD rates, with $39 \%$ of mothers meeting criteria for PPD, and an additional $16.9 \%$ showing symptoms of subsyndromal PPD 30 days after NICU admission. ${ }^{7}$ Mothers with PPD were significantly more anxious, hostile, and depressed, and they were more poorly adjusted than fathers in a study examining PPD in mother-father pairs of high-risk infants. ${ }^{26}$ However, mothers are not alone in this experience. A study of 35 fathers of infants in the NICU found that $60 \%$ of participants exhibited elevated depressive symptoms at baseline. ${ }^{27}$ The percentage of fathers experiencing depressive symptoms eventually decreased to $36 \%{ }^{27}$ 


\section{Etiology of PPD and risk factors within the NICU environment Etiology of PPD}

The etiology of PPD is not clearly understood, as no single causative factor has been determined. ${ }^{28}$ However, it is likely to be multifactorial, influenced by a combination of hormonal, psychosocial, and genetic factors. ${ }^{3}$ The biological changes in hormone levels during the postpartum period, combined with an individual's genetic and psychological predisposition, may represent the triggering event for PPD. ${ }^{4}$ Pearlstein et al also indicate that changes in hormones and sleep during the early postpartum period can represent a major vulnerability to the onset of PPD. ${ }^{29}$

\section{NICU environment}

Admission into the NICU can be a financial stressor. The financial burden of a NICU admission can be a significant problem for the family unit. ${ }^{6}$ Hospital charges for an initial NICU hospital stay average approximately $\$ 76,164$, with the cost of care for infants born prior to 32 weeks gestation averaging $\$ 280,811 .^{30}$

Having an infant in the NICU is also associated with stressful environmental and psychological factors. ${ }^{31}$ The environment of the NICU is often unfamiliar, highly technological, and seemingly unpredictable. Many aspects of the NICU experience can be distressing, including the sights and sounds of the unit, the infant's physical appearance, the medical equipment used, the medical terminology used by personnel, and the relationships between parents and health care personnel. ${ }^{7}$ Rogers et al found that the parental role alteration and the prolonged ventilation of the infant were related to the increased depressive symptoms reported by the mothers of the NICU infants. ${ }^{32}$

In the NICU, noise and light levels frequently exceed hospital recommendations. Lawson et al found that infants in the NICU are often exposed to excessive environmental stimulation, such as noise and light, at levels that are comparable to traffic on a street corner or inside a motorbus. ${ }^{33}$ The specific effects of high noise levels on infant development and the impact this has on PPD are unknown. ${ }^{34}$ Additionally, methodologically sound research is needed to further investigate the lasting effects of NICU admissions on infant development and PPD, to better inform hospital recommendations and requirements.

\section{Light exposure and depression}

Low lighting and minimal light exposure within the NICU could produce experiences of depression. Low levels of illumination at dawn or dusk are often associated with seasonal affective disorder. ${ }^{35}$ Neumeister et al found that light therapy decreased symptoms of depression by $35 \%$ when combined with antidepressant medication, ${ }^{36}$ and it was more effective than antidepressant drugs alone or placebo. ${ }^{37}$

Depression and the impact of light therapy have also been examined in women who have antepartum depression. Depression ratings can improve by up to $49 \%$ after bright light therapy. ${ }^{38}$ One published study examined the direct impact of light exposure on postpartum women. Wang et al examined 15 nondepressed postpartum women with a device used to capture light objectively through lux-light measurement. ${ }^{35}$ After 72 hours of measuring their typical exposure to light, light exposure and mood rating were compared to healthy control-matched women. ${ }^{35}$ No significant differences in mood were found between the amount of light experienced by women with PPD and those in the control group. ${ }^{35}$ It is important to document and measure how limited light exposure may impact the emotional well-being of NICU caregivers experiencing PPD. More research is needed to address this significant gap in the literature.

\section{Psychosocial factors of the NICU environment}

The mothers of NICU infants are impacted by the psychological factors, including concerns about long-term outcomes and/or survival of the infant, being separated from the infant, having an altered parental experience, feelings of limitations about their ability to care for the infant, and feelings of helplessness. ${ }^{28}$ The perception of losses in carrying out maternal roles has been identified as one of the most significant contributors to depressive symptoms for mothers. ${ }^{7}$ Increased psychological distress during NICU admissions is often associated with a decrease in the caregiver's perception of mastery of situational factors. ${ }^{39}$ This indicates to caregivers that their actions have little to no impact on these situational cues, making them more susceptible to experiences of distress, anxiety, and depression. ${ }^{39}$ Mothers of neonates in the NICU frequently encounter situations seemingly out of their control. They are likely to encounter more difficulty developing perceptions of mastery/control resulting in a higher risk of distress, anxiety, and depression. ${ }^{39}$ The NICU experience invokes environmental and psychological distress, which leads to a need for increased attention to this high-risk population. ${ }^{7,26,40,41}$

\section{Predictors and risk factors for PPD}

A number of major risk factors are significantly associated with the development of PPD. Findings in the general 
population have consistently shown the following major factors contributing to increased risk of PPD: lack of social support; ${ }^{42}$ previous history of depression; ${ }^{42}$ marital conflict; ${ }^{43}$ and stressful life events. ${ }^{44-46}$ Beck's 2001 meta-analysis identified low social support, maternal anxiety, and stress as the most significant predictors of PPD. ${ }^{47}$ These risk factors have been extensively examined among mothers of healthy, full-term infants. However, there is little literature investigating the risk factors and differing experiences of mothers of NICU infants. Thus, the studies reviewed in this article focus upon significant predictors that are specific to mothers of NICU infants, in contrast to the predictors that have been examined in only the mothers of healthy infants in the general population.

Several studies provide evidence of psychosocial variables as a risk factor for PPD (Table 2). Sociodemographic factors, such as poverty, low social support, high levels of stress, and low maternal education, have been implied as predictors of PPD for mothers of preterm or LBW infants. ${ }^{24,28,46,49}$ Other predictors include the perception of staff support, ${ }^{28}$ marital status, ${ }^{32}$ and parental role alteration. ${ }^{32,48}$

One of the strongest predictors of PPD among mothers of preterm and LBW infants is lack of social support, or perceived lack of social support. ${ }^{24,28}$ Among mothers of preterm infants, lack of social support was a significant predictor of depression, along with self-esteem and closeness to partner. ${ }^{49}$ When social support was rated as more important during the postpartum period, depression increased. ${ }^{50}$ Social isolation has been suggested as the strongest predictor of PPD, aside from antenatal psychological distress. ${ }^{51}$ Mothers with higher levels of social support show greater decreases in depressive symptoms over time. ${ }^{52}$

However, some studies contradict social support as a predictor for PPD. Davis et al found that social support had no significant correlation with depressive symptoms. ${ }^{28}$ Instead, perception of nurse support had a significant inverse relationship with depressive symptoms among mothers of preterm infants in the NICU. ${ }^{28}$ Life stressors and maternal level of education were the most significant variables correlated with depressive symptoms. ${ }^{28}$ De Magistris et al compared risk factors of PPD among mothers of NICU infants and mothers of healthy term infants. Neither group showed a correlation between PPD and socioeconomic level, educational level, family environment, presence of a stable partner, work environment, or interests away from work and friendships. ${ }^{53}$ Lower gestational age, longer length of stay at the NICU, and more serious clinical problems were significantly correlated with elevated depressive symptoms. ${ }^{53}$
Rogers et al assessed the role of social support in depression and anxiety among mothers of preterm infants at the time of discharge from a level III NICU. ${ }^{32}$ Social support was not a significant risk factor, but experiencing parental role alteration, increased time of infant on life support, and marital status were associated with increased PPD symptoms. ${ }^{32}$ Since previous research has shown that unmarried mothers more frequently endorse PPD symptomatology, this finding was surprising. ${ }^{32}$ Further, no correlation between previous history of depression and current symptoms had previously been identified as a predictor of PPD. ${ }^{32,42,47,54}$

Contrastingly, a history of prior depression/anxiety has been consistently found to be predictive of PPD within the general population. ${ }^{55}$ However, this has not been confirmed in cohorts of mothers with preterm infants or infants admitted to the NICU. ${ }^{32}$ While mothers with high depression scores are more likely to have spontaneous preterm birth, ${ }^{25}$ the literature has not adequately addressed whether a history of depression is predictive of PPD for mothers of infants admitted to the NICU. Rogers et al found that a prior history of depression and anxiety was not correlated with maternal symptoms of PPD while infants were hospitalized in the NICU. ${ }^{32}$

A longitudinal exploration of predictors of depressive trajectories among the mothers of NICU infants found that the racial and ethnic minority mothers experienced increased depressive symptoms after an initial steep decline of symptoms following discharge from the NICU. ${ }^{56}$ Mothers with sociodemographic risks, such as poverty and low education, had elevated depressive symptoms, and their symptoms did not decrease over time.

Ethnicity, age, and maternal education have not been consistently related to maternal postpartum symptoms of depression. ${ }^{32}$ Race and ethnicity other than white have been associated with higher rates of PPD in the general population. ${ }^{57}$ Asian and African American mothers are significantly more likely to develop PPD. ${ }^{58}$ Sociodemographic and maternal stressors are related to increased rates of PPD in African American and Hispanic mothers when compared with white mothers. ${ }^{59}$ Asian/Pacific Islander mothers are three times more likely to develop PPD than are other ethnicities, even when controlling for sociodemographic and maternal stressor variables. ${ }^{59}$

Depressive symptoms are thought to be associated with lower gestational age, lower birth weight, longer length of stay at NICU, and severity of illness..$^{24,41,53,56,60}$ African Americans have at least twice the rate of preterm birth than that of whites, as well as the overall greatest risk of preterm birth. ${ }^{32}$ However, Rogers et al found no difference 
in the rate of PPD between African American and white mothers. ${ }^{32}$

Medical risk status, age, and the infant's developmental outcome contribute to the psychosocial impact of mothers having infants in the NICU. ${ }^{61}$ Mothers of NICU infants have more complicated patterns of psychological symptoms than healthy term mothers. ${ }^{61}$ Future research should examine the contribution of these population factors to PPD and consider these factors when interpreting the results and making recommendations.

\section{PPD diagnosis and screening Diagnosis of PPD}

The diagnosis of PPD is complicated by not only a lack of understanding, but also varying definitions of the diagnosis itself. The Diagnostic and Statistical Manual of Mental Disorders 4th edition (DSM-IV) defined PPD as a Major Depressive Disorder (MDD) subtype, which has an onset 1 month following delivery. Criteria include five or more of the following, lasting 2 weeks or longer: depressed mood or loss of interest or pleasure in activities; loss of energy; feelings of worthlessness or guilt; symptoms of sleep disturbance; diminished concentration; and thoughts of suicide. ${ }^{62}$ The DSM-V, released in May 2013, listed PPD as a specifier (with peripartum onset) of the MDD, if the onset of mood symptoms presents during pregnancy or within 4 weeks following delivery. ${ }^{63}$ Under the International Classification of Diseases-9, PPD falls under the code of 648.44 Mental Disorders of Mother, postpartum condition or complication.

According to Alici-Evcimen and Sudak, PPD differs from MDD in the time of onset, frequency of suicidal thoughts and behavior, higher rate of anxiety symptoms, and existence of obsessive, aggressive thoughts about the infant. ${ }^{3}$ A frequent and distinctive symptom of PPD includes excessive concern about the well-being of the neonate, which can range from hyperinvolvement and unjustified fears about the infant to delirium that is associated with physically injuring the child. ${ }^{46}$

Although the DSM-IV and DSM-V require symptoms to occur within the first month after delivery, some researchers maintain that the first three postpartum months are a high-risk period for the development of psychiatric illnesses, specifically PPD. ${ }^{4}$ The Agency for Healthcare Research and Quality indicated that symptoms of major and minor depression occur throughout the first year after childbirth. ${ }^{64}$ Research has consistently shown that $10 \%-15 \%$ of women experience clinically significant depressive symptomatology after childbirth. More than $60 \%$ of these women have symptom onset within 6 weeks postpartum. ${ }^{65}$ Mothers of preterm infants are especially at risk. The Centers for Disease Control and Prevention reported that mothers of preterm infants have higher rates of PPD and are at notable risk, with rates between $14 \%-27 \%{ }^{1}$

Additionally, it is important to note the possibility of other forms of psychological illness in the NICU setting. The current literature has explored the occurrence of acute stress disorder, adjustment disorder, posttraumatic stress disorder, and some forms of anxiety disorder, which we will not elaborate upon in this review. ${ }^{66-68}$

The literature provides evidence of immediate adverse effects of PPD on maternal-infant interaction, as well as PPD's long-term effects on infant cognitive and emotional development. ${ }^{69}$ The recognition, prevention, and treatment of PPD is currently an area of noted public health significance, due to these significant negative effects. ${ }^{29}$ In response to PPD's negative outcomes for children, the American Academy of Pediatrics released a report recommending that pediatricians screen mothers for PPD at 1-, 2-, and 4-month visits. $^{70}$ Additionally, the Association of Women's Health, Obstetric, and Neonatal Nurses recommends that PPD screening mechanisms be available in all facilities that serve pregnant women, new mothers, and newborns. ${ }^{67,71}$

\section{Screening PPD in the NICU}

The NICU experience increases the number of stressors a mother faces in the immediate postnatal period. These stressors, coupled with the previously mentioned risk factors, contribute to the development of PPD among mothers of infants in the NICU. When assessing rates of PPD, it is important to consider the type of tool used, since findings may vary depending on the selected assessment tool, such as psychiatric screening versus the Edinburgh Postnatal Depression Scale (EPDS). Table 1 provides a summary of the screening instruments mentioned in this review.

An effective PPD screening program must address four fundamental questions: 1) which screening instrument to use; 2) who should screen; 3) when to screen; and 4) how to use the results of the screening. ${ }^{72}$ Variability and uncertainty are associated with each of these questions. ${ }^{72}$ The American Academy of Pediatrics recommends using either the EPDS with a cutoff score of at least 10, or a two-question screen. The two-question screen asks: 1) Over the past 2 weeks, have you ever felt down, depressed, or hopeless?; and 2) Over the past 2 weeks, have you felt little interest or pleasure in doing things? The screen is considered positive if either of the questions is 
Table I PPD screening instruments

\begin{tabular}{|c|c|c|c|c|}
\hline Title & \# of items, length/type & Availability & Administration & $\begin{array}{l}\text { Used in } \\
\text { NICU }\end{array}$ \\
\hline ANRQ & 9 multiple choice items & Public & Self-report & Not applicable \\
\hline$\left.B D\right|^{45,81}$ & 21 items, 4-point Likert scale & Purchase & Self-report & Yes \\
\hline BPDS & $\begin{array}{l}\text { I0 items, open-ended and } \\
\text { yes/no questions }\end{array}$ & Purchase & Self-report & No \\
\hline CES-D ${ }^{48,59}$ & 20 items & Public & Self-report & No \\
\hline EPDS $^{29,42,51,52,68,84,88,91}$ & I0 items & Public & Self-report & Yes \\
\hline $\mathrm{GHQ}^{47}$ & $12,28,30,60$ item versions & Purchase & Self-report & No \\
\hline HRSD & 17 or 21 item versions & Public & Health care professional & Yes \\
\hline IDS & 35 items & Public & Self-report & No \\
\hline LQ & 24 items & Public & Self-report & No \\
\hline PDSS $25,43,73,74$ & 35 items & Purchase & Self-report & Yes* \\
\hline PHQ & 2 or 9 item versions & Public & Self-report & Not applicable \\
\hline QIDS & 16 items & Public & Self-report & Yes \\
\hline SCL-90-R ${ }^{82}$ & 90 items & Public & Self-report & Yes \\
\hline Zung SDS & 20 items & Public & Self-report & No \\
\hline
\end{tabular}

Notes: *Psychometric properties of instrument were studied in NICU setting. Not all instruments listed were used in the studies described in this review. Abbreviations: PPD, postpartum depression; NICU, neonatal intensive care unit; ANRQ, Antenatal Risk Questionnaire; BDI, Beck Depression Inventory; BPDS, Bromley Postnatal Depression Scale; CES-D, Center for Epidemiological Studies Depression Scale; EPDS, Edinburgh Postpartum Depression Scale; GHQ, General Health Questionnaire; HRSD, Hamilton Rating Scale for Depression; IDS, Inventory of Depressive Symptomatology; LQ, Leverton Questionnaire; PDSS, Postpartum Depression Screening Scale; PHQ, Patient Health Questionnaire; QIDS, Quick Inventory of Depressive Symptoms; SCL-90-R, Symptom Checklist-90-R; Zung SDS, Zung Self-Rating Depression Scale.

answered affirmatively. A positive screen indicates a risk of PPD; further evaluation is needed to diagnose it.

As the current standard of care, the EPDS has good clinical acceptability and is an appropriate tool for universal perinatal depression screening. ${ }^{73}$ Further, recommendations have been made for the use of the EPDS as an aid for assessing a mother's mood alongside professional judgment and a clinical interview. ${ }^{74}$ Most of the studies included in this review used the EPDS. ${ }^{75-77}$ Despite its popularity, the EPDS lacks items focused on motherhood and has been shown to produce significant false negative and false positive results. ${ }^{78}$ The United Kingdom National Screening Committee's current policy states that evidence does not support the use of current screening tools. ${ }^{74}$ The committee holds that screening should not be offered due to false positives. ${ }^{74}$

The Postpartum Depression Screening Scale (PDSS) is a 35-item instrument that uses a Likert response scale and has been studied within the NICU setting. The PDSS has shown good reliability and validity. ${ }^{79} \mathrm{McCabe}$ et al found that the psychometric properties of the PDSS were supported in mothers of NICU infants. ${ }^{80}$ Additionally, Blucker et al found preliminary validation of a 15-item version of the PDSS in the NICU setting. ${ }^{81}$ However, the PDSS is lengthy and timeconsuming, and it lacks an item relating to harming others or the infant. ${ }^{79}$ Previous research has supported the PDSS as a promising tool for PPD screening, although future research is needed to obtain further qualitative data for the PDSS to be incorporated as part of a routine screening process in the NICU setting. ${ }^{81,82}$
A common limitation in studies of PPD is the use of selfreport measures, which are prone to response bias related to the phenomenon of social desirability. It is believed that this can also play a strong role in this particular population with instruments measuring PPD. The mothers may feel defensive or under- or overreport their PPD symptoms. The mothers may feel the need to fulfill a certain maternal role, so they may self-report information that is congruent with the socially desirable maternal role, but it may not accurately capture PPD symptoms. ${ }^{83}$ This response bias may contribute to the possibility of a high false positive rate of depressive symptoms in the included studies.

To address the issue with self-report data, future research could include clinical interviews to objectively assess levels of stress and depression. Using the Postpartum Assessment Instrument, Yurdakul et al developed a semistructured interview covering the major correlates outlined by the literature. ${ }^{40}$ It was used to assess mothers within the context of pregnancy and postpartum experiences. ${ }^{40}$ This screening method allows for direct one-on-one interaction, access to body language, and rapport building between the interviewer and the interviewee, although further research to ensure its validity is needed. ${ }^{40}$ The inclusion of a semistructured interview provides a more thorough and reliable assessment of the mothers' mental health. ${ }^{40,61}$ Clinical observations of mother-infant interactions can also be a powerful tool; however, only one of the reviewed studies incorporated such objective measurement. ${ }^{56}$

According to a review of the efficacy and safety of PPD screening, the effectiveness of screening is associated 
Table 2 Prevalence of PPD in the NICU

\begin{tabular}{|c|c|c|c|c|}
\hline References & Study design & Sample & $\begin{array}{l}\text { Screening } \\
\text { instruments }\end{array}$ & Results \\
\hline $\begin{array}{l}\text { Carter et al } \\
(2007)^{23}\end{array}$ & $\begin{array}{l}\text { Prospective } \\
\text { longitudinal study } \\
\text { of random sample }\end{array}$ & $\begin{array}{l}\mathrm{N}=636 ; 447 \text { parents (mother and } \\
\text { father with NICU infant), } \\
\text { I } 89 \text { parents (mother and father } \\
\text { of full term non-NICU infant) }\end{array}$ & EPDS & $\begin{array}{l}\text { No significant difference on mean } \\
\text { EPDS (scores between control } \\
\text { group and NICU group) }\end{array}$ \\
\hline $\begin{array}{l}\text { Blucker et al } \\
(2013)^{81}\end{array}$ & Factor analysis & $\begin{array}{l}\mathrm{N}=385 \text { mothers of } \mathrm{NICU} \\
\text { infants }\end{array}$ & PDSS & $\begin{array}{l}\text { 36\% Positive PPD screenings } \\
30 \% \text { At-risk for PPD }\end{array}$ \\
\hline $\begin{array}{l}\text { Davis et al } \\
(2003)^{28}\end{array}$ & Population study & $\begin{array}{l}\mathrm{N}=62 \text { mothers of preterm } \\
\text { infants }\end{array}$ & EPDS & $40 \%$ Significant PPD symptoms \\
\hline $\begin{array}{l}\text { De Magistris } \\
\text { et al }(2010)^{53}\end{array}$ & Comparative & $\begin{array}{l}\mathrm{N}=213 \text {; II3 mothers of NICU } \\
\text { infants, } 100 \text { mothers of } \\
\text { healthy infants }\end{array}$ & EPDS & $\begin{array}{l}23 \% \text { Mothers of NICU infants had } \\
\text { positive PPD screenings } \\
8 \% \text { Mothers of healthy infants had } \\
\text { positive PPD screenings }\end{array}$ \\
\hline $\begin{array}{l}\text { Doering et al } \\
(1999)^{26}\end{array}$ & $\begin{array}{l}\text { Comparative } \\
\text { design }\end{array}$ & $\begin{array}{l}\mathrm{N}=165 \text { mother-father pairs } \\
\text { of high-risk NICU neonates }\end{array}$ & $\begin{array}{l}\text { Psychosocial } \\
\text { Adjustment to Illness } \\
\text { Scale (family version) }\end{array}$ & $\begin{array}{l}\text { Mothers: poorer psychosocial adjustment } \\
\text { Mothers and fathers both have } \\
\text { heightened distress and poor } \\
\text { psychosocial adjustment in NICU }\end{array}$ \\
\hline $\begin{array}{l}\text { Gillaspy et al } \\
(2010)^{69}\end{array}$ & Correlational & $\begin{array}{l}\mathrm{N}=\text { I I I mothers of NICU } \\
\text { infants }\end{array}$ & PDSS & $\begin{array}{l}\text { 52.3\% Positive PPD screenings } \\
29.7 \% \text { Significant PPD symptoms }\end{array}$ \\
\hline $\begin{array}{l}\text { Lefkowtiz } \\
\text { et al }(2010)^{7}\end{array}$ & & $\begin{array}{l}\mathrm{N}=127 ; 86 \text { mothers of NICU } \\
\text { infants, } 4 \mathrm{I} \text { fathers of NICU } \\
\text { infants }\end{array}$ & PDSS & $\begin{array}{l}\text { 39\% Positive PPD screenings } \\
\text { 16.9\% Subsyndromal PPD } \\
\text { 16\% Positive PTSD and PPD screenings }\end{array}$ \\
\hline $\begin{array}{l}\text { Mew et al } \\
(2003)^{52}\end{array}$ & Correlational & $\begin{array}{l}\mathrm{N}=39 \text { mothers of preterm } \\
\text { infants }\end{array}$ & $\begin{array}{l}\text { CES-D; } \\
\text { PSS: NICU }\end{array}$ & $\begin{array}{l}50 \% \text { At-risk for PPD at baseline } \\
20 \% \text { At-risk for PPD at } 6 \text { months } \\
\text { corrected age }\end{array}$ \\
\hline $\begin{array}{l}\text { Meyer et al } \\
(1995)^{90}\end{array}$ & Correlational & $\begin{array}{l}\mathrm{N}=142 \text { mothers of } \mathrm{NICU} \\
\text { infants }\end{array}$ & $\begin{array}{l}\text { PSS; } \\
\text { Symptom } \\
\text { Checklist } 90-\mathrm{R}\end{array}$ & $\begin{array}{l}28 \% \text { Mothers of NICU infants had clinically } \\
\text { significant levels of psychological distress } \\
10 \% \text { Mothers in normative comparison } \\
\text { population had clinically significant levels } \\
\text { of psychological distress }\end{array}$ \\
\hline $\begin{array}{l}\text { Rogers et al } \\
(2012)^{32}\end{array}$ & $\begin{array}{l}\text { Prospective cohort } \\
\text { study }\end{array}$ & $\begin{array}{l}\mathrm{N}=73 \text { mothers of preterm } \\
\text { infants }\end{array}$ & $\begin{array}{l}\text { EPDS; } \\
\text { PSS:NICU }\end{array}$ & $\begin{array}{l}20 \% \text { Clinically significant levels of PPD } \\
43 \% \text { Moderate to severe anxiety }\end{array}$ \\
\hline $\begin{array}{l}\text { Ukpong et al } \\
(2003)^{4 I}\end{array}$ & $\begin{array}{l}\text { Cross-sectional } \\
\text { prospective study }\end{array}$ & $\begin{array}{l}\mathrm{N}=60 ; 33 \text { mothers of preterm } \\
\text { infants, } 27 \text { mothers of full } \\
\text { term infants }\end{array}$ & $\begin{array}{l}\text { GHQ-30; } \\
\text { BDI }\end{array}$ & $\begin{array}{l}27.3 \% \text { Mothers of preterm infants had } \\
\text { significant emotional distress } \\
3.7 \% \text { Mothers of full term infants } \\
\text { had significant emotional distress }\end{array}$ \\
\hline $\begin{array}{l}\text { Yurdakul et al } \\
(2009)^{40}\end{array}$ & Case-control study & $\begin{array}{l}\mathrm{N}=169 ; 81 \text { mothers of } \mathrm{NICU} \\
\text { infants, } 81 \text { mothers of healthy } \\
\text { term infants }\end{array}$ & $\begin{array}{l}\text { PAI; } \\
\text { EPDS }\end{array}$ & $\begin{array}{l}29.5 \% \text { NICU mothers had high depression } \\
\text { scores } \\
\text { I3.6\% Control mothers had high } \\
\text { depression scores }\end{array}$ \\
\hline
\end{tabular}

Note: Study design was not determined independently, but it was stated by researchers of each study.

Abbreviations: PPD, postpartum depression; EPDS, Edinburgh Postpartum Depression Scale; PDSS, Postpartum Depression Screening Scale; NICU, neonatal intensive care unit; PTSD, posttraumatic stress disorder; PSS, Parental Stressor Scale; GHQ, General Health Questionnaire; BDI, Beck Depression Inventory; PAI, Postpartum Assessment Instrument; CES-D, Center for Epidemiological Studies Depression Scale.

with the availability of follow-up systems for women with positive PPD results. ${ }^{72}$ While the screening process itself may be relatively easy to implement, depending on the size of the NICU, it can be difficult to ensure that the women who are referred receive the appropriate follow-up services. This can require dedicated staff time and resources, and it is critical to a successful PPD screening program. It is important that providers be aware of referral resources in the community. Toward that end, it is highly beneficial to recruit a NICU social worker or other contact person to facilitate consistent and continuous follow-up for the patient. ${ }^{69}$

\section{Interventions for PPD Educational and psychosocial interventions for PPD}

Few studies focus on intervention and prevention for PPD in the NICU setting. The optimal treatment plan for any mother with PPD involves a coordinated disciplinary team and a holistic, family-centered approach. ${ }^{84}$ Evidence-based 
treatments for PPD include cognitive-behavioral therapy and interpersonal psychotherapy in individual and group settings, supportive counseling, psychoeducation, and antidepressant medications, including serotonin-specific reuptake inhibitors. The mainstay of treatment has included antidepressant therapy, alone or coupled with psychotherapy. ${ }^{85}$ Combined psychotherapy and psychopharmacology are recommended for the treatment of symptoms and relational components of moderate-to-severe PPD. ${ }^{85}$ Mothers of preterm infants can experience high stress levels and feelings of helplessness in the NICU, and they often lack an adequate knowledge of how to parent and interact with their infants during the hospital stay. Therefore, providing parental education during the NICU admission could be beneficial. The following paragraphs introduce different modes of intervention.

Melnyk et al conducted an intervention focused on an educational-behavioral intervention program called Creating Opportunities for Parent Empowerment (COPE). ${ }^{86}$ This program consists of four intervention sessions that focus on the infant's appearance, behavioral characteristics, parenting education, and training. ${ }^{86} \mathrm{COPE}$ includes activities that implement the learned information. To measure efficacy, feasibility, and acceptability of the intervention, mothers participated in COPE and were given basic intervention services, including information on hospital services, immunization services, and discharge. ${ }^{86}$ Mothers who completed the COPE program reported less maternal stress in the NICU; stronger parental beliefs; more positive parent-infant interactions in the NICU; less maternal anxiety and fewer depressive symptoms after hospitalization; and a reduced length of hospital stay for preterm infants, compared with the control group. ${ }^{86}$ In addition, participation in the program resulted in decreased costs for the families and the hospital. ${ }^{86}$

Another promising and cost-effective intervention for PPD was conducted by Barry and Singer. ${ }^{87}$ They investigated the impact of a journal writing exercise on depressive and posttraumatic stress symptoms on mothers with an infant in the NICU. ${ }^{87}$ The mothers wrote about the most emotional and upsetting experiences of the NICU. The mothers who engaged in the exercise showed an improvement in symptom levels over time. ${ }^{87}$ Journal writing was particularly beneficial for mothers who might not have had access to any formal mental health services or assistance in coping with the NICU experience. ${ }^{87}$ This exercise appears to be a cost-effective, manageable, and successful way to expand intervention services for mothers experiencing any level of distress. Hospital staff could recommend journal writing to mothers during and after their infant's stay in the NICU, particularly those mothers who lack access to other mental health services or who are at risk for the development of PPD. Further research will show whether this activity is an effective intervention for PPD.

Examining the intervention strategies in low-income mothers of preterm infants is particularly important, since these families can experience a multitude of psychosocial barriers. Silverstein et al specifically targeted low-income mothers in a feasibility intervention consisting of oneon-one sessions of problem-solving education (PSE). ${ }^{88}$ Intervention group mothers of NICU infants were taught how to brainstorm goals, evaluate solutions, and plan action for a measurable problem. ${ }^{88}$ Depression symptoms, perceived stress, and social functioning were assessed over a 6-month follow-up period. ${ }^{88}$ The mothers receiving the PSE intervention were less likely to experience an episode of moderately severe depression symptoms; they had less stress and better overall functioning than mothers in the control group. ${ }^{88}$ This PSE intervention is easy to administer and can be delivered by providers without formal mental health experience. ${ }^{88}$ Its theory-based approach is easily replicable and applicable during and immediately following a child's NICU stay. ${ }^{88}$

\section{Family-based and provider focused interventions}

Interventions focusing on the implementation and the role of NICU nurses are thought to be significant and have a strong positive impact on the mothers of NICU infants. ${ }^{89}$ Morey and Gregory evaluated the impact of a nurse-led intervention in the NICU for high-risk pregnant women. ${ }^{89}$ The components of this intervention included a video, education about and discussion of the NICU, and a tour of the NICU. ${ }^{89}$ Education about the NICU covered general hospital and NICU information from management staff, input from parents of NICU graduates, and the clinical aspects and care requirements of premature infants. ${ }^{89}$ The intervention significantly decreased maternal stressors related to sights and sounds of the NICU environment. ${ }^{88}$ Appropriate infant behavior and appearance increased. ${ }^{89}$ The multiple time points and educational component of this intervention likely play a role in mitigating maternal stressors, which may lead to preventing the development of PPD or reducing symptoms. In addition, the involvement of the providers may contribute to alleviating maternal stress.

Meyer et al examined the use of a family-based, individualized intervention to decrease maternal stress and depression..$^{90}$ The individualized treatment plan was developed by a clinician and an interdisciplinary team using the Clinical Interview for Parents of High Risk Infants. ${ }^{90}$ 
Specifically, the intervention program assessed families of preterm infants during their transition from hospitalization to home on the following: infant behavior and characteristics; family organization and functioning; caregiving environment; home discharge; and community resources.$^{90}$ The intervention was found to significantly alleviate depressive symptoms. ${ }^{90}$ Only $11 \%$ of mothers receiving the intervention had depressive symptoms at discharge, compared with $44 \%$ of mothers receiving treatment as usual which included medical and nursing treatment of the infant along with assignment of a social worker. ${ }^{90}$ More mothers in the intervention group showed decreases in the level of depression than did those in the control group. ${ }^{90}$ Mothers in the intervention group had distinctly lower levels of stress at discharge compared with baseline. ${ }^{90}$ Mothers in the control group found no relief in their level of stress from baseline to discharge. ${ }^{90}$ The individualized aspect of the intervention makes it difficult to determine which components of the intervention induced positive effects, but it reiterates the potential benefits of individualized intervention..$^{90}$

Psychosocial family-based interventions seem to improve maternal PPD psychological well-being, regardless of the challenge in replication. Future research should use a larger sample, as well as assess whether these positive effects continue past the early newborn period. All aforementioned interventions are outlined in Table 3.

\section{Role of health care providers in NICU}

The potential utility of nurses and of other NICU providers in the prevention/detection of PPD and easing the overall NICU experience for mothers has been established. ${ }^{28,91,92}$ Perception of nurse support had a significant inverse relationship with depressive symptoms, reiterating that nurses are a vital resource for mothers of NICU infants. ${ }^{28}$ Amankwaa et al note that NICU nurses have ample opportunity to observe mother-infant interactions daily, allowing for further identification of mothers who may need services or extra support. ${ }^{92}$ Additionally, mothers could benefit from nurses who have been educated about the complex nature of maternal stress and depressive symptoms in the NICU, as the nurses would then be able to more appropriately identify mothers at higher risk for developing PPD. ${ }^{91}$

There is a great need to advocate for routine screening procedures and to incorporate them in the NICU setting. As screening programs are implemented, systems for appropriate referrals for further assessment, intervention, and clinical services are critical. This process requires the support of both
NICU providers and hospital administrators. An essential first step in this process is to begin to provide psychosocial education for NICU providers and hospital administration about the prevalence of PPD in the NICU, its impact, and the benefits of screening and intervention programs.

\section{Limitations, gaps, and future research \\ Limitations of articles reviewed}

Overarching limitations were apparent in the literature. Small sample sizes and the use of convenience samples greatly limit the generalizability and applicability of study findings. Future research would benefit from larger sample sizes and greater diversity in study populations. Not all studies used control groups; this affects the interpretation of the majority of study findings. There is also a need for longitudinal research assessing and examining PPD in caregivers at the time of NICU admission. Additionally, there is a lack of research examining the after effects of PPD and the effects of the NICU environment on caregiver and infant psychological, psychosocial, and physical well-being.

\section{Gaps in current literature}

Research is needed to determine the most appropriate and effective way to screen for PPD in the NICU. Four primary research questions remain to be answered: 1) which screening instrument to use; 2) which provider should screen; 3) when to screen; and 4) how to use the results of the screening. ${ }^{72}$ The lack of studies examining the psychometric properties of existing PPD screening instruments in the context of the NICU represents a significant gap in the literature. Currently, there are no guidelines available regarding the most appropriate time to screen, or who should be responsible for screening. Although the literature calls for a need to implement PPD screening in the NICU, it is unclear how best to use the results of screening. In our own work, significant difficulties arise when attempting to make appropriate referrals to the community. This has been especially true with regard to mental health referrals for mothers whose insurance coverage is ending or who have no insurance coverage.

\section{Future research directions}

Future research should focus on three primary areas: 1) PPD and NICU hospital course; 2) NICU PPD screening programs; and 3) NICU PPD intervention programs. Although there is substantial evidence of the adverse impact of PPD and maternal depression on infants, there is a need for research to determine the impact of PPD on maternal behavior during 


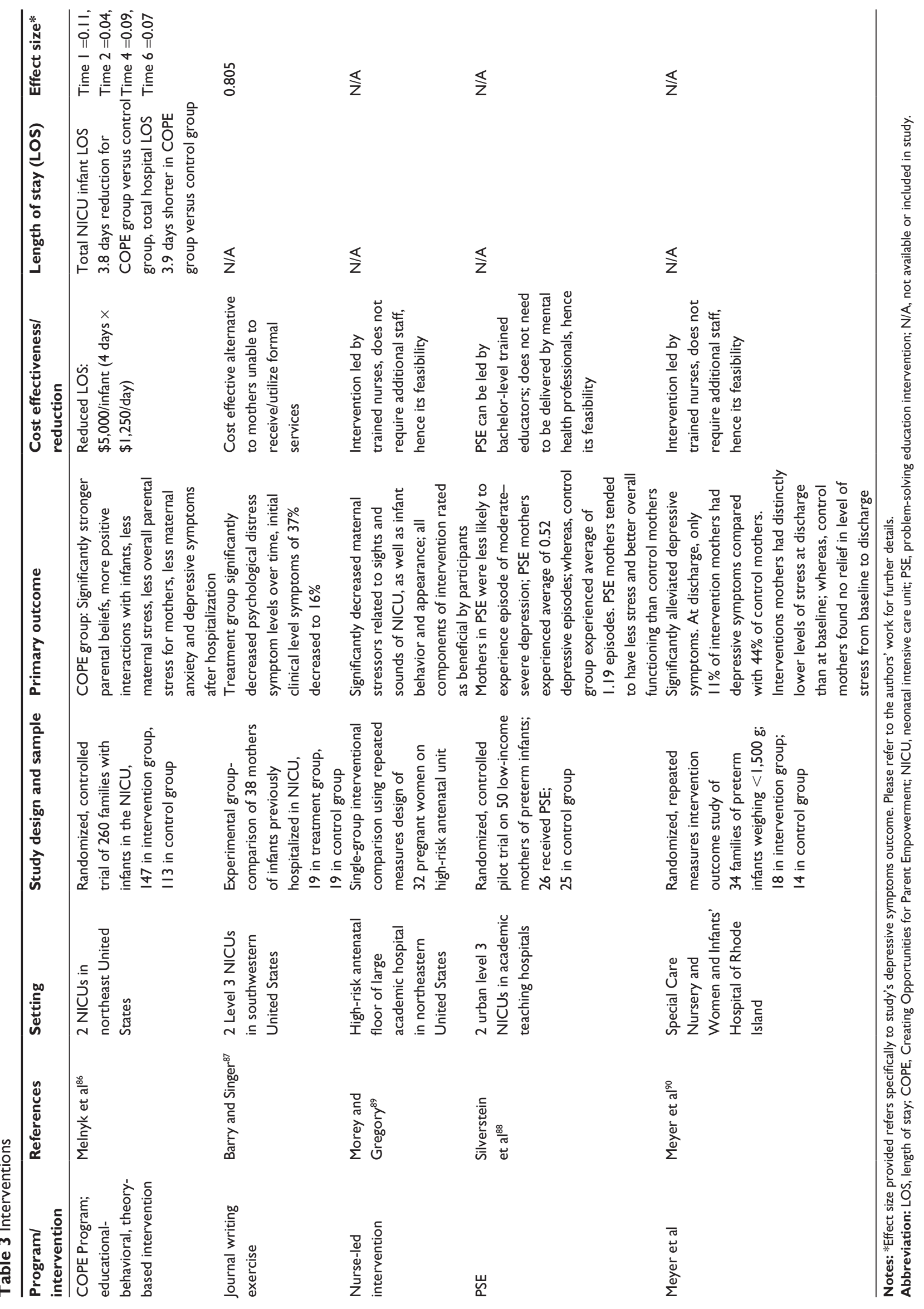


the NICU admission and the NICU hospital course. Further study is needed to determine the mechanisms involved in the NICU/PPD relationship. Future investigations should examine if PPD screening programs in the NICU result in improved clinical outcomes, reduced health care utilization, and increased quality of life for both mother and child.

\section{Discussion}

We reviewed several creative prevention and intervention programs designed specifically for the NICU. These programs have produced a significant reduction in maternal distress, often specifically a reduction in PPD symptomatology. We commend the research teams for their efforts and call for more research in this area. It will not be sufficient to determine if an intervention results in a reduction in PPD symptoms. We must also discover if the intervention results in reduced health care utilization and cost savings.

In terms of health care utilization, the infant is the patient admitted to the NICU, while the infant's mother is not a patient of the NICU. Screening, intervention, and prevention efforts for PPD in the NICU are not currently reimbursable by insurance, because these efforts are targeted at the mother. For PPD screening and intervention programs to become customary and sustainable, researchers must demonstrate a reduction in health care utilization and decreased hospital costs resulting from those efforts.

The literature provides us with a list of risk factors that can be used to identify mothers who require special attention and formal mental health services. By implementing regular screenings for PPD, we can target mothers who need intervention earlier and reduce their chances of developing PPD symptomatology. Proactive involvement of NICU staff and health care professionals is another critical strategy for the prevention and identification of mothers at risk for developing PPD. With larger and more diverse sample sizes, improved PPD assessment measures, and observations of mother-infant interactions, we will achieve more powerful results than those found in the current research. This will refine our understanding of these mothers' needs, thereby determining the types of prevention and intervention services necessary to improve the well-being of this population and the development of their infants.

\section{Disclosure}

The authors report no conflicts of interest in this work.

\section{References}

1. Centers for Disease Control and Prevention (CDC). Prevalence of self-reported postpartum depressive symptoms - 17 states, 2004-2005. MMWR Morb Mortal Wkly Rep. 2008;57(14):361-366.
2. Miller LJ, Rukstalis M. Beyond the "Blues": Hypotheses about postpartum reactivity. In: Miller L, editor. Postpartum Mood Disorders. 1st ed. Washington, DC: American Psychiatry Press; 1999:3-20.

3. Alici-Evcimen Y, Sudak DM. Postpartum depression. Prim Care Update Ob Gyns. 2003;10(5):210-216.

4. Newport DJ, Hostetter A, Arnold A, Stowe ZN. The treatment of postpartum depression: minimizing infant exposures. $J$ Clin Psychiatry. 2002;63 Suppl 7:31-44.

5. Beck CT. The effects of postpartum depression on maternal-infant interaction: a meta-analysis. Nurs Res. 1995;44(5):298-304.

6. Bicking C, Moore GA. Maternal perinatal depression in the neonatal intensive care unit: the role of the neonatal nurse. Neonatal Netw. 2012;31(5):295-304.

7. Lefkowitz DS, Baxt C, Evans JR. Prevalence and correlates of posttraumatic stress and postpartum depression in parents of infants in the Neonatal Intensive Care Unit (NICU). J Clin Psychol Med Settings. 2010;17(3):230-237.

8. Saigal S, den Ouden L, Wolke D, et al. School-age outcomes in children who were extremely low birth weight from four international population-based cohorts. Pediatrics. 2003;112(4):943-950.

9. Bhutta AT, Cleves MA, Casey PH, Cradock MM, Anand KJ. Cognitive and behavioral outcomes of school-aged children who were born preterm: a meta-analysis. JAMA. 2002;288(6):728-737.

10. McGrath M, Sullivan M. Birth weight, neonatal morbidities, and school age outcomes in full-term and preterm infants. Issues Compr Pediatr Nurs. 2002;25(4):231-254.

11. O'Brien F, Roth S, Stewart A, Rifkin L, Rushe T, Wyatt J. The neurodevelopmental progress of infants less than 33 weeks into adolescence. Arch Dis Child. 2004;89(3):207-211.

12. Reiss AL, Kesler SR, Vohr B, et al. Sex differences in cerebral volumes of 8-year-olds born preterm. J Pediatr. 2004;145(2):242-249.

13. Gross SJ, Mettelman BB, Dye TD, Slagle TA. Impact of family structure and stability on academic outcome in preterm children at 10 years of age. J Pediatr. 2001;138(2):169-175.

14. Sinclair D, Murray L. Effects of postnatal depression on children's adjustment to school. Teacher's reports. Br J Psychiatry. 1998;172: 58-63.

15. Weissman MM, Paykel ES. The Depressed Woman: A Study of Social Relations. Chicago, IL: University of Chicago Press; 1974.

16. Beck CT. The lived experience of postpartum depression: a phenomenological study. Nurs Res. 1992;41(3):166-170.

17. Cohn JF, Tronick EZ. Three-month-old infants' reaction to simulated maternal depression. Child Dev. 1983;54(1):185-193.

18. Field TM. Early interactions between infants and thier postpartum depressed mothers. Infant Behavior and Development. 1984;7(4): 517-522.

19. Field T, Healy B, Goldstein S, et al. Infants of depressed mothers show "depressed" behavior even with nondepressed adults. Child Dev. 1988;59(6):1569-1579.

20. Whiffen VE, Gotlib IH. Infants of postpartum depressed mothers: temperament and cognitive status. J Abnorm Psychol. 1989;98(3): 274-279.

21. Cox AD, Puckering C, Pound A, Mills M. The impact of maternal depression in young children. J Child Psychol Psychiatry. 1987;28(6): 917-928.

22. Weissman MM, Paykel ES, Klerman GL. The depressed woman as a mother. Social Psychiatry. 1972;7(2):98-108.

23. Carter JD, Mulder RT, Frampton CM, Darlow BA. Infants admitted to a neonatal intensive care unit: parental psychological status at 9 months. Acta Paediatr. 2007;96(9):1286-1289.

24. Vigod SN, Villegas L, Dennis CL, Ross LE. Prevalence and risk factors for postpartum depression among women with preterm and low-birthweight infants: a systematic review. BJOG. 2010;117(5): 540-550.

25. Mounts KO. Screening for maternal depression in the neonatal ICU. Clin Perinatol. 2009;36(1):137-152.

26. Doering LV, Dracup K, Moser D. Comparison of psychosocial adjustment of mothers and fathers of high-risk infants in the neonatal intensive care unit. J Perinatol. 1999;19(2):132-137. 
27. Mackley AB, Locke RG, Spear ML, Joseph R. Forgotten parent: NICU paternal emotional response. Adv Neonatal Care. 2010;10(4): 200-203.

28. Davis L, Edwards H, Mohay H, Wollin J. The impact of very premature birth on the psychological health of mothers. Early Hum Dev. 2003;73(1-2):61-70.

29. Pearlstein T, Howard M, Salisbury A, Zlotnick C. Postpartum depression. Am J Obstet Gynecol. 2009;200(4):357-364.

30. Special Care Nursery Admissions [webpage on the Internet]. March of Dimes Perinatal Data Center. National Perinatal Information System/Quality Analytic Services; 2011. Available from: http:// www.marchofdimes.com/peristats/pdfdocs/nicu_summary_final.pdf. Accessed February 18, 2013.

31. Trombini E, Surcinelli P, Piccioni A, Alessandroni R, Faldella G. Environmental factors associated with stress in mothers of preterm newborns. Acta Paediatr. 2008;97(7):894-898.

32. Rogers CE, Kidokoro H, Wallendorf M, Inder TE. Identifying mothers of very preterm infants at-risk for postpartum depression and anxiety before discharge. J Perinatol. 2013;33(3):171-176.

33. Lawson KL, Daum C, Turkewitz G. Environmental characteristics of a neonatal intensive care unit. Child Dev. 1977;48(4):1633-1639.

34. Lasky RE, Williams AL. Noise and light exposures for extremely low birth weight newborns during their stay in the neonatal intensive care unit. Pediatrics. 2009;123(2):540-546.

35. Wang EJ, Kripke DF, Stein MT, Parry BL. Measurement of illumination exposure in postpartum women. BMC Psychiatry. 2003;3:5.

36. Neumeister A, Goessler R, Lucht M, Kapitany T, Bamas C, Kasper S. Bright light therapy stabilizes the antidepressant effect of partial sleep deprivation. Biol Psychiatry. 1996;39(1):16-21.

37. Bendetti F, Colombo C, Pontiggia A, Bernasconi A, Florita M, Smeraldi E. Morning light treatment hastens the antidepressant effect of citalopram: a placebo-controlled trial. J Clin Psychiatry. 2003;64(6): 648-653.

38. Oren DA, Wisner KL, Spinelli M, et al. An open trial of morning light therapy for treatment of antepartum depression. Am J Psychiatry. 2002;159(4):666-669.

39. Eshbaugh EM. Maternal age and depressive symptoms in a low-income sample. J Community Psychol. 2008;36(3):399-409.

40. Yurdakul Z, Akman I, Kuşçu MK, et al. Maternal psychological problems associated with neonatal intensive care admission. Int $J$ Pediatr. 2009;2009:591359.

41. Ukpong DI, Fatoye FO, Oseni SB, Adewuya AO. Post partum emotional distress in mothers of preterm infants: a controlled study. East Afr Med J. 2003;80(6):289-292.

42. Bernazzani O, Saucier JF, David H, Borgeat F. Psychosocial predictors of depressive symptomatology level in postpartum women. J Affect Disord. 1997;46(1):39-49.

43. O’Hara MW, Schlechte JA, Lewis DA, Varner MW. Controlled prospective study of postpartum mood disorders: psychological, environmental, and hormonal variables. J Abnorm Psychol. 1991;100(1):63-73.

44. Terry DJ, Mayocchi L, Hynes GJ. Depressive symptomatology in new mothers: a stress and coping perspective. J Abnorm Psychol. 1996;105(2):220-231.

45. Paykel ES, Cooper Z, Ramana R, Hayhurst H. Life events, social support and marital relationships in the outcome of severe depression. Psychol Med. 1996;26(1):121-133.

46. Areias ME, Kumar R, Barros H, Figueiredo E. Correlates of postnatal depression in mothers and fathers. Br J Psychiatry. 1996;169(1):36-41.

47. Beck CT. Predictors of postpartum depression: an update. Nurs Res. 2001;50(5):275-285.

48. Johnstone SJ, Boyce PM, Hickey AR, Morris-Yatees AD, Harris MG. Obstetric risk factors for postnatal depression in urban and rural community samples. Aust N Z J Psychiatry. 2001;35(1):69-74.

49. Logsdon MC, Usui W. Psychosocial predictors of postpartum depression in diverse groups of women. West J Nurs Res. 2001;23(6):563-574.
50. Logsdon MC, McBride AB, Birkimer JC. Social support and postpartum depression. Res Nurs Health. 1994;17(6):449-457.

51. Nielsen Forman D, Videbech P, Hedegaard M, Dalby Salvig J, Secher NJ. Postpartum depression: identification of women at risk. BJOG. 2000;107(10):1210-1217.

52. Mew AM, Holditch-Davis D, Belyea M, Miles MS, Fishel A. Correlates of depressive symptoms in mothers of preterm infants. Neonatal Netw. 2003;22(5):51-60.

53. De Magistris A, Coni E, Puddu M, Zonza M, Fanos V. Screening of postpartum depression: comparison between mothers in the neonatal intensive care unit and in the neonatal section. J Matern Fetal Neonatal Med. 2010;23 Suppl 3:101-103.

54. Miles MS, Holditch-Davis D, Schwartz TA, Scher M. Depressive symptoms in mothers of prematurely born infants. J Dev Behav Pediatr. 2007;28(1):36-44.

55. Lancaster CA, Gold KJ, Flynn HA, Yoo H, Marcus SM, Davis MM. Risk factors for depressive symptoms during pregnancy: a systematic review. Am J Obstet Gynecol. 2010;202(1):5-14.

56. Poehlmann J, Schwichtenberg AJ, Bolt D, Dilworth-Bart J. Predictors of depressive symptom trajectories in mothers of preterm or low birth weight infants. J Fam Psychol. 2009;23(5): 690-704

57. Horowitz JA, Murphy CA, Gregory KE, Wojcik J. A communitybased screening initiative to identify mothers at risk for postpartum depression. J Obstet Gynecol Neonatal Nurs. 2011;40(1): $52-61$.

58. Melville JL, Gavin A, Guo Y, Fan MY, Katon WJ. Depressive disorders during pregnancy: prevalence and risk factors in a large urban sample. Obstet Gynecol. 2010;116(5):1064-1070.

59. Liu CH, Tronick E. Rates and predictors of postpartum depression by race and ethnicity: results from the 2004 to 2007 New York City PRAMS survey (Pregnancy Risk Assessment Monitoring System). Matern Child Health J. 2013;17(9): 1599-1610.

60. Carter JD, Mulder RT, Bartram AF, Darlow BA. Infants in a neonatal intensive care unit: parental response. Arch Dis Child Fetal Neonatal Ed. 2005;90(2):F109-F113.

61. Singer LT, Salvator A, Guo S, Collin M, Lilien L, Baley J. Maternal psychological distress and parenting distress after birth of a very lowbirth-weight infant. JAMA. 1999;281(9):799-805.

62. American Psychiatric Association. Diagnostic and Statistical Manual of Mental Disorders, Text Revision (DSM-IV-TR). 4th ed. Arlington, VA: American Psychiatric Association; 2000.

63. American Psychiatric Association. Diagnostic and Statistical Manual of Mental Disorders, Text Revision (DSM-IV-TR). 5th ed. Arlington, VA: American Psychiatric Association; 2013.

64. Gaynes BN, Gavin N, Meltzer-Brody S, et al. Perinatal depression: prevalence, screening accuracy, and screening outcomes. Evid Rep Technol Assess (Summ). 2005;(119):1-8.

65. Stowe ZN, Nemeroff CB. Women at risk for postpartum-onset major depression. Am J Obstet Gynecol. 1995;173(2):639-645.

66. Shaw RJ, Deblois T, Ikuta L, Ginzburg K, Fleisher B, Koopman C. Acute stress disorder among parents of infants in the neonatal intensive care nursery. Psychosomatics. 2006;47(3):206-212.

67. Shaw RJ, Bernard RS, Deblois T, Ikuta LM, Ginzburg K, Koopman C. The relationship between acute stress disorder and posttraumatic stress disorder in the neonatal intensive care unit. Psychosomatics. 2009;50(2):131-137.

68. Zelkowitz P, Bardin C, Papageorgiou A. Anxiety affects the relationship between parents and their very low birth weight infants. Infant Ment Health J. 2007;28(2):296-313.

69. McCaffree MA, Cherry A, Gillaspy S, Hetherington C. The contribution of postpartum psychosocial variables to infant length of stay in the neonatal intensive care unit. Poster presented at: American Academy of Pediatrics, National Conference and Education Meeting-Perinatal Section; October 2-5, 2010, San Francisco, CA. 
70. Earls MF; Committee on Psychosocial Aspects of Child and Family Health American Academy of Pediatrics. Incorporating recognition and management of perinatal and postpartum depression into pediatric practice. Pediatrics. 2010;126(5):1032-1039.

71. Schaar GL, Hall M. A nurse-led initiative to improve obstetricians'screening for postpartum depression. Nurs Womens Health. 2013;17(4):306-316.

72. Myers ER, Aubuchon-Endsley N, Bastian LA, et al. Efficacy and Safety of Screening for Postpartum Depression. Comparative Effectiveness Review 106. Rockville, MD: Agency for Healthcare Research and Quality; 2013.

73. Gemmill AW, Leigh B, Ericksen J, Milgrom J. A survey of the clinical acceptability of screening for postnatal depression in depressed and non-depressed women. BMC Public Health. 2006;6:211.

74. The UK NSC policy on Postnatal depression screening in pregnancy [webpage on the Internet]. London: UK National Screening Committee, Public Health England; 2013. Available from: http:/www.screening. nhs.uk/postnataldepression. Accessed March 2, 2013.

75. Cox JL, Holden JM, Sagovsky R. Detection of postnatal depression. Development of the 10-item Edinburgh Postnatal Depression Scale. Br J Psychiatry. 1987;150:782-786.

76. Davies BR, Howells S, Jenkins M. Early detection and treatment of postnatal depression in primary care. J Adv Nurs. 2003;44(3):248-255.

77. Fergerson SS, Jamieson DJ, Lindsay M. Diagnosing postpartum depression: can we do better? Am J Obstet Gynecol. 2002;186(5):899-902.

78. Adams C. Use of the Edinburgh Postnatal Depression Scale. Community Practitioner. 2002;75(4):142.

79. Barrick C, Kent V, Crusse E, Taylor D. Psychometric assessment of the Correa-Barrick Postpartum Depression Scale. J Affect Disord. 2012;141(2-3):246-254.

80. McCabe K, Blucker R, Gillaspy JA Jr, et al. Reliability of the postpartum depression screening scale in the neonatal intensive care unit. Nurs Res. 2012;61(6):441-445.

81. Blucker RT, Gillaspy JA Jr, Jackson D, et al. Postpartum Depression in the NICU: An examination of the factor structure of the Postpartum Depression Screening Scale. Advances in Neonatal Care. In press 2013.
82. Hanusa BH, Scholle SH, Haskett RF, Spadaro K, Wisner KL. Screening for depression in the postpartum period: a comparison of three instruments. J Womens Health (Larchmt). 2008;17(4):585-596.

83. Holden R. Social Desirability. The Corsini Encylopedia of Psychology. 1-2: John Wiley \& Sons, Inc.; 2010.

84. Horowitz JA, Goodman JH. Identifying and treating postpartum depression. J Obstet Gynecol Neonatal Nurs. 2005;34(2):264-273.

85. Epperson CN. Postpartum major depression: detection and treatment Am Fam Physician. 1999;59(8):2247-2254, 2259-2260.

86. Melnyk BM, Feinstein NF, Alpert-Gillis L, et al. Reducing premature infants' length of stay and improving parents' mental health outcomes with the Creating Opportunities for Parent Empowerment (COPE) neonatal intensive care unit program: a randomized, controlled trial. Pediatrics. 2006;118(5):e1414-e1427.

87. Barry LM, Singer GHS. Reducing Maternal Psychological Distress After the NICU Experience Through Journal Writing. J Early Interv. 2001;24(4):287-297.

88. Silverstein M, Feinberg E, Cabral H, et al. Problem-solving education to prevent depression among low-income mothers of preterm infants: a randomized controlled pilot trial. Arch Womens Ment Health. 2011;14(4):317-324.

89. Morey J, Gregory K. Nurse-led education mitigates maternal stress and enhances knowledge in NICU. MCN Am J Matern Child Nurs. 2012;37(3):182-191.

90. Meyer EC, Coll CT, Lester BM, Boukydis CF, McDonough SM, Oh W. Family-based intervention improves maternal psychological well-being and feeding interaction of preterm infants. Pediatrics. 1994;93(2): 241-246.

91. Gennaro S, Brooten D, Roncoli M, Kumar SP. Stress and health outcomes among mothers of low-birth-weight infants. West J Nurs Res. 1993;15(1):97-113.

92. Amankwaa LC, Pickler RH, Boonmee J. Maternal Responsiveness in Mothers of Preterm Infants. Newborn and Infant Nursing Reviews 2007;7(1):25-30.
International Journal of Women's Health

\section{Publish your work in this journal}

The International Journal of Women's Health is an international, peerreviewed open-access journal publishing original research, reports, editorials, reviews and commentaries on all aspects of women's healthcare including gynecology, obstetrics, and breast cancer. The manuscript management system is completely online and includes

\section{Dovepress}

a very quick and fair peer-review system, which is all easy to use. Visit http://www.dovepress.com/testimonials.php to read real quotes from published authors. 